\title{
Fiber Reinforced Concrete for repairing and strengthening RC structures: some recent advancements
}

\author{
Giovanni A. Plizzari ${ }^{1, *}$ \\ ${ }^{1}$ University of Brescia, DICATAM, 25123 Brescia, Italy
}

\begin{abstract}
Enhancement of seismic behaviour of existing structures, both masonry or reinforced concrete, is a key issue for future technical activities in many Western Countries, since construction of new buildings has decreased in favour of an increased attention to the structural rehabilitation and re-use of existing buildings. The development of innovative repairing, strengthening, and retrofitting techniques is, therefore, a crucial topic to improve the structural safety of existent constructions. Fibre Reinforced Concrete (FRC) may now be particularly efficient in these cases, due to the high toughness provided by fibres that may reduce or avoid the use of conventional reinforcement.This paper presents the results of two experimental research studies carried out at the University of Brescia, concerning the use of FRC as the principal reinforcing material. The first study aims at assessing the structural response, under cyclic horizontal loads, of a full scale (1:1) Unreinforced Masonry (URM) building retrofitted with Steel Fibre Reinforced Mortar (SFRM) as external plaster. The second study concerns the seismic retrofitting of a scaled (1:4) reinforced concrete bridge pier by means of a High Performance Fibre Reinforced Concrete (HPFRC) jacketing. In both cases, repair material is applied in thin layers, due to the high mechanical properties compared to those of the respective substrates, with the addition of a limited amount of traditional reinforcement, placed only on the most stressed sections.
\end{abstract}

\section{Introduction}

One of the major challenges in civil Engineering is nowadays represented by the rehabilitation of structures built in the sixties and in the seventies that are now 4050 years old. However, structural rehabilitation can take advantage of the different new materials studied during the last 20-30 years that are widely available into the market.

Among these, Fibre Reinforced Concrete (FRC) may represent a efficient solution for different structural elements $[1,2]$ also considering that research studies carried out worldwide allowed FRC to enter into structural codes of different Countries as well as in the fib Model Code 2010 [3]. Moreover, fibres reduce the width of possible potential cracks. This remarkably influences the structural durability since a new long service life of the structure can start after the application of these materials.

FRC efficiency depends on its post-cracking mechanical properties that reduce or avoid the use of conventional reinforcement. Existing structures are better strengthened by FRC having an enhanced residual post-cracking strength either with softening or hardening behaviour. These materials are know in the scientific literature as High Performance FRC (HPFRC).

Among existing structures, unreinforced masonry (URM) characterizes most of residential buildings that were usually designed to withstand only vertical loads. The heterogeneity of masonry constructions, the low tensile strength and shear resistance of materials determine the high seismic vulnerability of these buildings. Although several experimental studies have been carried out on this topic $[4,5,6,7,8,9,10]$, the literature provides a limited number of case studies concerning tests on full scale buildings made with hollow-clay brick masonry.

Aim of the present paper is to shed some new lights on structural rehabilitation of two typical existing structures through the use of FRC as external jacket.

The first case study concerns a masonry house made of hollow-clay brick having mechanical properties typical of existing masonry buildings constructed in Italy between the " $50 \mathrm{~s}$ and $70 \mathrm{~s}$ of the 20 th century. In particular, the research aims at proposing the use of a thin new plaster made of Steel Fibres Reinforced Mortar (SFRM) as strengthening material. The FRC plaster is applied on the external surfaces of the building with a thickness of $25 \mathrm{~mm}$. Except for some local additional rebars placed in the areas of the building with higher stresses, the only reinforcement of the SFRM overlay is represented by steel fibres.

Besides masonry buildings, ageing of RC road infrastructures (e.g. bridges, tunnels, etc.), built mainly between the " $60 \mathrm{~s}$ and the $70 \mathrm{~s}$, is rapidly becoming a critical topic for road and highway administrators of

* Corresponding author: giovanni.plizzari@unibs.it 
many Countries. Despite the lack of updated information concerning the state of health of infrastructure, it is already known that, given the age of these infrastructures, the increased traffic load as well as the growing awareness of seismic risk, there is an urgent need for structural retrofitting. As a matter of fact, many existing bridges were not designed for seismic resistance and they do not satisfy the minimum safety requirements of current design codes [11].

For this reason, the second case study concerns a bridge pier strengthened with a thin jacket of High Performance Fibre Reinforced Concrete (HPFRC). The latter may represent, in many practical cases, a cost effective solution for seismic retrofitting.

The bridge pier behaviour was analytically predicted and experimentally verified, before and after the application of the HPFRC jacketing, on a large specimen representing a real bridge pier in a scale 1:4.

\section{Masonry buildings}

An experimental study based on quasi-static reverse cyclic test of a full scale URM building reinforced by SFRM coating is in progress in the Laboratory of Civil Engineering of the University of Brescia. A preliminary experimental study of full scale URM walls reinforced with SFRM [12] showed that the adoption of this material is a promising technology for both improving the seismic response of undamaged masonry walls and for their repair after an earthquake. In view of the promising wall test results, a preliminary numerical study has been carried out to predict the structural response. The two story hollow-clay brick masonry building with wooden floor and pitched roof is depicted in Figure 1.
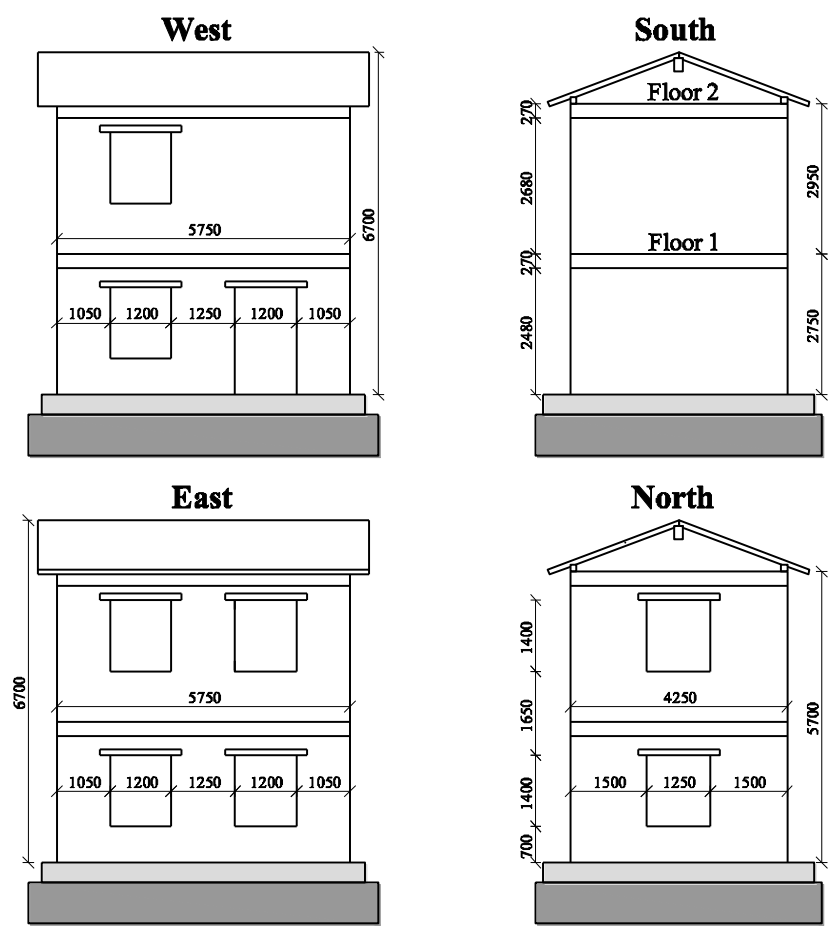

Fig. 1. Geometry of the full scale building.
The building is made of bricks with vertical holes, laid in a single wythe with $10 \mathrm{~mm}$ thick mortar joints and with a nominal thickness of $200 \mathrm{~mm}$. This type of bricks, characterized by a high percentage of vertical holes $(60 \%)$, was chosen to better represent the low resistance of several existing buildings. The plan dimension is $5.75 \times 4.25 \mathrm{~m}$ and the total height is $6.7 \mathrm{~m}$, with non-symmetric openings. The floor structure is made of $120 \mathrm{~mm}$ wide and $140 \mathrm{~mm}$ high wood joists placed every $500 \mathrm{~mm}$ with $30 \mathrm{~mm}$ thick planks on the top.

In order to prevent the occurrence of out-of-plane failure mechanisms, a rigid diaphragm connected to the reinforced concrete spandrel beam, inserted in the masonry wall thickness, was designed. The seismic floor diaphragm is made of a $50 \mathrm{~mm}$ thick reinforced concrete slab connected to the wood joists by steel dowels (Ø16 mm@200 mm). The roof structure includes one $160 \mathrm{~mm} \times 260 \mathrm{~mm}$ ridge beam, two $120 \mathrm{~mm} \times 140 \mathrm{~mm}$ spreader beam on the top of the longitudinal walls and $80 \mathrm{~mm} \times 100 \mathrm{~mm}$ purlins every $500 \mathrm{~mm}$, forming two pitches with $30 \mathrm{~mm}$ thick planks. In the numerical model the roof was considered for the loads that it applies on the structure.

\subsection{Numerical model}

In order to predict the global response of the full scale building, Non-Linear Finite Element Analyses (NLFEAs) have been carried out with the Finite Element (FE) program DIANA 10.1. The analyses provided important data to better understand the parameters that affect the resistance of the construction and the collapse mechanisms.

\subsubsection{Constitutive model}

NLFEAs were carried out by using a total strain rotating crack model to describe a crack pattern having cracks on unknown locations. A parabolic constitutive law in compression, depending on compressive strength $f_{c}$ and compressive fracture energy $G_{c}$, and the Hordijk model for cracked concrete in tension, depending on tensile strength $f_{t}$ and Mode-I fracture energy $G_{\text {If }}$, were adopted for masonry. A Von Mises yield criterion was adopted for steel rebars, assuming a yield stress $\mathrm{f}_{\mathrm{ym}}=510 \mathrm{MPa}$ and a tensile strength $\mathrm{f}_{\mathrm{tm}}=610 \mathrm{MPa}$. Finally, about the compressive behavior of SFRM, the Thorenfeldt model, depending on compressive strength $\mathrm{f}_{\mathrm{c}}$, was used.

For the tensile behaviour, three point bending tests (3PBT) on notched specimens $\left(40 \times 150 \times 500 \mathrm{~mm}^{3}\right)$ under CMOD (Crack Mouth Opening Displacement) control were carried out to obtain the Nominal stress-CMOD curves. The constitutive stress-crack width law representing the tensile behavior of SFRM material was obtained by means of a back analysis. The numerical simulation showed that a tri-linear curve, whose shape is depicted in Figure 2, is suitable for reproducing the postcracking response of mortar. The Nominal stress-CMOD diagram of Figure 3 compares the experimental and 
numerical results, indicating a reasonably good agreement.

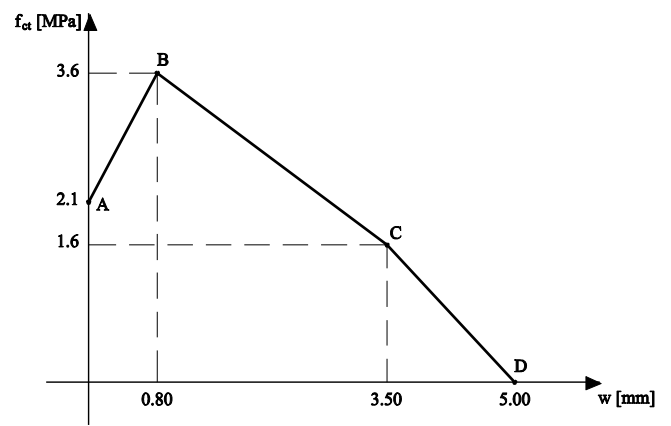

Fig. 2. Trilinear curve of SFRM coating.

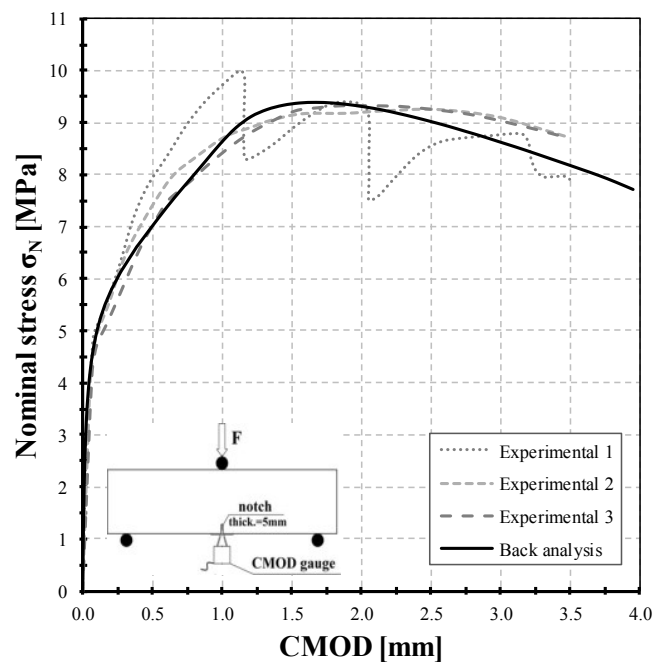

Fig. 3. Back analysis of 3PBTs: Experimental vs numerical Nominal stress - CMOD curves.

\subsubsection{Model validation}

In order to validate the smeared crack model used for the simulation of the building, four full scale walls tested at the University of Brescia have been preliminary simulated by means of NLFEAs. The specimens were $1970 \mathrm{~mm}$ high, $2995 \mathrm{~mm}$ long, $240 \mathrm{~mm}$ thick and consisted of vertically perforated bricks laid in a single wythe with $10 \mathrm{~mm}$ thick mortar joints. In more detail, the walls named as MWH1 and MWH2 were notstrengthened, whereas the walls MWH1-R and MWH2$\mathrm{R}$ were retrofitted with a $25 \mathrm{~mm}$ thick layer of SFRM coating applied on both sides of the wall. Figure 4 reports the comparison between experimental and numerical lateral load-deflection curves; it can be noticed that the results obtained from NLFEAs are in good agreement with the experimental results in term of maximum load, whereas the initial stiffness is slightly overestimated.

The higher stiffness of the numerical curves may be due to the assumption of perfect SFRM-to-masonry bond adhesion. Regarding MWH2-R wall, the overestimation of the peak load may be partly due to the assumption of perfect bond between coating and the rebars used as connections with the foundation.

The good agreement between the experimental and numerical crack patterns (plotted in terms of tensile cracking strain) is shown in Figure 5. The unstrengthened wall (MWH1) showed a diagonal shear failure, while the wall reinforced by SFRM coating on both surfaces (MWH1-R) exhibited a flexural crack running along the interface between the wall and the foundation beam, typical of the rocking mechanism. The wall MWH2-R was characterized by more cracks in SFRM coating than the wall MWH1-R. The crack pattern showed splitting cracks along the steel rebars and the widespread cracking of the wall surface was connected to vertical and $45^{\circ}$ inclined cracks observed during the experimental test.

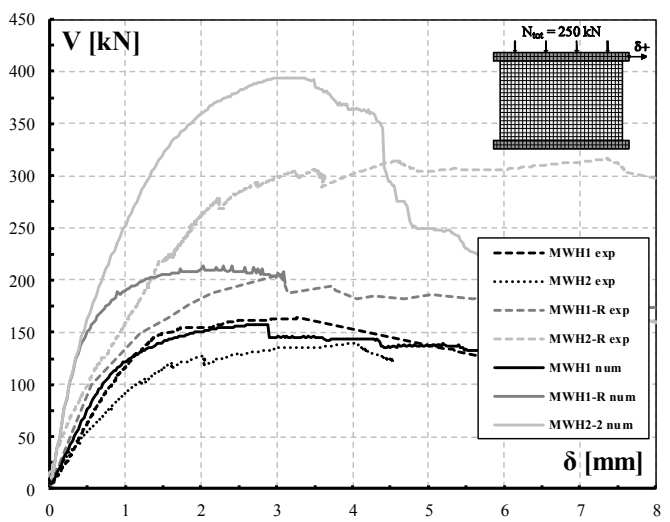

Fig. 4. Lateral load-deflection response of the walls: comparison between experimental and numerical results.

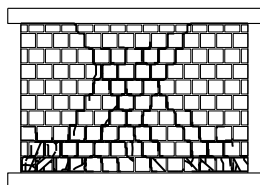

(a): MWH1

experimental

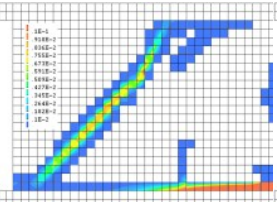

(b): MWH1 numerical

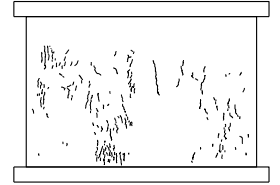

(c): MWH1-R experimental

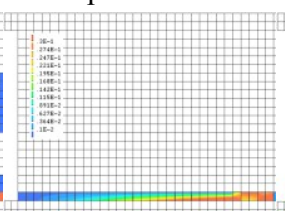

(d): MWH1-R numerical

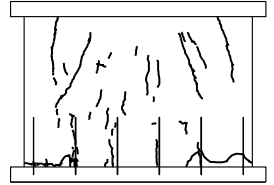

(e): MWH2-R experimental

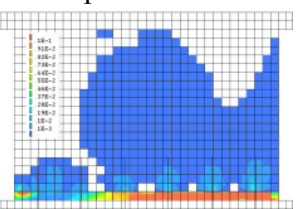

(f): MWH2-R

numerical
Fig. 5. Experimental crack patterns (a, c, e) and numerical contours of principal tensile post-cracking strains $(b, d, f)$.

\subsubsection{Simulation of the full-scale building}

Figure 6 shows the mesh adopted for the full scale building modeling. The un-strengthened masonry walls, the concrete beams and slabs of the floors were modelled with CQ40S elements, having $2 \times 2 \times 7$ Gaussian integration scheme and average dimension of $100 \mathrm{~mm}$. Likewise masonry walls simulated in the previous section, the strengthened masonry was modelled with CQ40L elements, assuming perfect SFRM-to-masonry bond. Reinforcement bars were used to model the steel rebars of concrete beams and the SFRM coating-tofoundation connections, assuming perfect steel-to-mortar bond.

In addition to self-weight of the masonry walls and concrete beams, uniform distributed loads were applied 
to represent the vertical loads present. The floor load was applied on the two longitudinal walls (East and West), due to the wood joist direction. Half of the roof load was applied on the longitudinal walls and half on the transverse ones (North and South). The masonry gable load was distributed on the two transverse walls.

The floor loads were calculated considering a total load equal to $\mathrm{G} 1+\mathrm{G} 2+0.3 \cdot \mathrm{Q}$, where $\mathrm{G} 1=1.45 \mathrm{kN}$ is the permanent load, $\mathrm{G} 2=2 \mathrm{kN}$ is the superimposed load and $\mathrm{Q}=2 \mathrm{kN}$ is the variable load. Only permanent load was considered for second floor. Finally, the roof loads was equal to $\mathrm{G} 1+\mathrm{G} 2$, where $\mathrm{G} 1=0.27 \mathrm{kN}$ and $\mathrm{G} 2=0.6 \mathrm{kN}$. The non-linear push-over analyses were run under indirect displacement control by means of arc-length technique. According to Italian building code, two loading distributions were taken into account in the preliminary parametric analyses: one proportional to first eigenvector and one to floor mass. The second one is more representative for a two-story masonry building because it emphasizes damage at the ground floor of the structure. For this reason, four concentrated horizontal forces acting along $\mathrm{x}$ direction and proportional to floor mass were applied to simulate seismic actions during the full scale test. Horizontal load was applied on the South wall for the positive loading direction and on the North one for the negative loading direction. In both cases, two forces were applied at the ends of each floor. A regular Newton-Raphson iteration scheme was adopted. The response of the building before and after the application of a single layer of SFRM coating has been studied. The simulations include one analysis on an un-strengthened building (MB) and two analyses on buildings (MB-R and $\mathrm{MB}-\mathrm{R}+\mathrm{SR}$ ) retrofitted with a $25 \mathrm{~mm}$ thick coating layer applied on the building façades. Unlike MB-R, MB$\mathrm{R}+\mathrm{SR}$ was provided with steel connections (Ø8 mm @ $500 \mathrm{~mm}$ ) between the SFRM coating and the concrete foundation of the building.

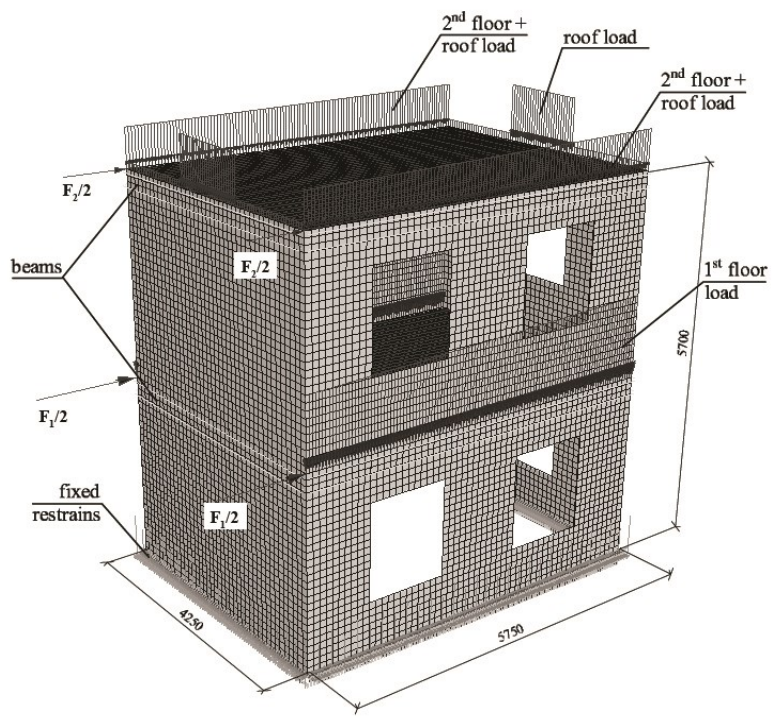

Fig. 6. Numerical model of the full scale building.

Figure 7 shows the comparison between the lateral loaddisplacement curves obtained from the three analyses for the positive loading direction. The strength and stiffness improvement provided by the proposed technique is highlighted by the initial branch of the response. In fact, the increase of the lateral capacity and of the initial stiffness of MB-R (as compared to MB) was $98 \%$ and $129 \%$ respectively. Moreover, the lateral capacity of $\mathrm{MB}-\mathrm{R}+\mathrm{SR}$ is approximately two times higher than the one obtained from the building without SFRM-tofoundation connections (MB-R). The steel rebars, in fact, preventing the masonry walls overturning, allowed to exploit the tensile toughness of SFRM, which better contributed to the resistance mechanisms of the building.

Figure 8 shows the comparison between the crack patterns of the East and South façades of the three buildings at collapse. The tensile cracking strains refer to the external masonry layer for $\mathrm{MB}$, and to the external coating layer for MB-R and MB-R+SR.

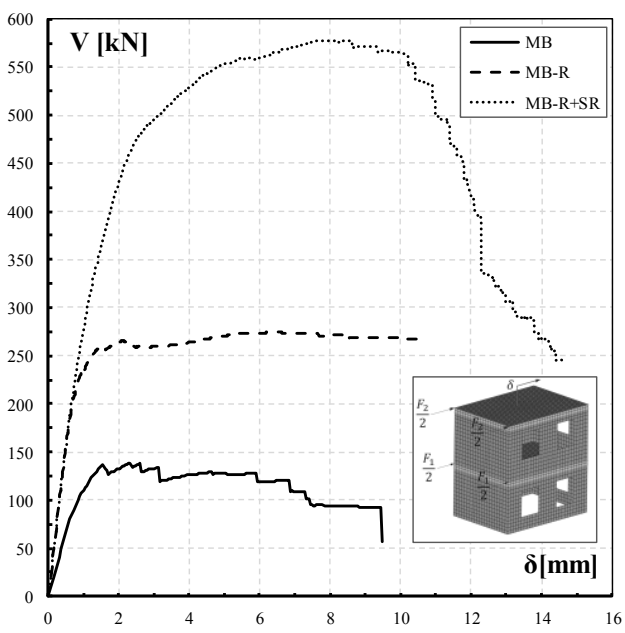

Fig. 7. Load-displacement curves: comparison between the three analyses on building.

The un-strengthened building showed a diagonal shear failure, while MB-R exhibited a rocking mechanism. The proposed technique led to a more ductile behavior of the structure. At the same lateral displacement, a marked decrease in cracking is observed due to the introduction of the reinforcement. As previously mentioned, the steel rebars placed along the building base to anchor the SFRM coating to foundation allowed to reach a peak load two times higher than the one obtained from the building MB-R. The strong increase of lateral resistance caused a greater cracking of SFRM coating. The numerical crack pattern of building $\mathrm{MB}-\mathrm{R}+\mathrm{SR}$ shows that a rocking mechanism occurs, with flexural horizontal cracks at the top and bottom ends of the piers of the ground floor between the openings. However, for higher horizontal loads, also diagonal cracking occurred in the latter and in the spandrels at first floor level, causing the significant reduction of the lateral capacity. 


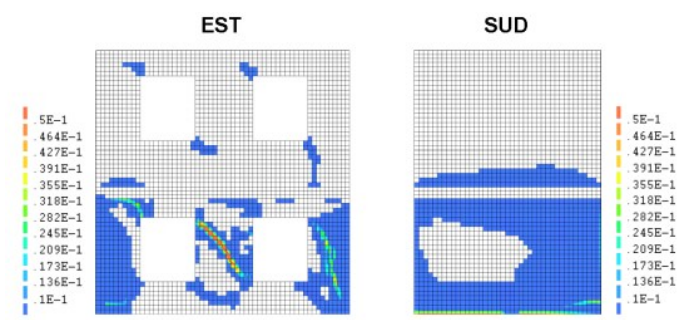

(a): $\mathrm{MB}$

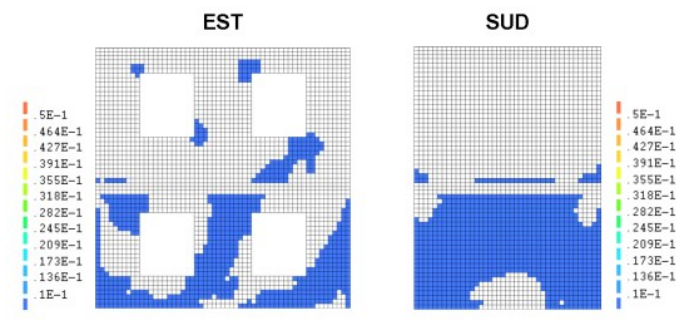

(b): MB-R

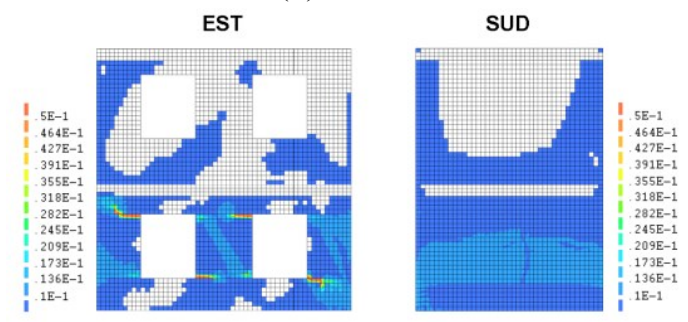

(c): $\mathrm{MB}-\mathrm{R}+\mathrm{SR}$

Fig. 8. Contours of principal tensile post-cracking strains of East and South façades of the building.

\subsection{Experimental test}

\subsubsection{Test rig}

Figure 9 depicts the test rig that was adopted to carry out the quasi-static reverse cyclic test on the two-story hollow-clay brick (HCB) masonry building with wooden floor and pitched roof. The horizontal loading distribution adopted for the test is proportional to floor mass (because it is more representative for a two-story masonry building), emphasizing damage at the ground floor of the structure. For this reason, two concentrated horizontal forces acting along N-S direction and proportional to floor mass were adopted during the fullscale test to simulate seismic actions. The two forces were applied in the middle of the spandrel beam of each floor. A distributor steel beam was designed to apply the $60 \%$ of the total load, provided by the electro-mechanic jack, at the first floor and the $40 \%$ of the total load at the second floor, as shown in Figure 9.

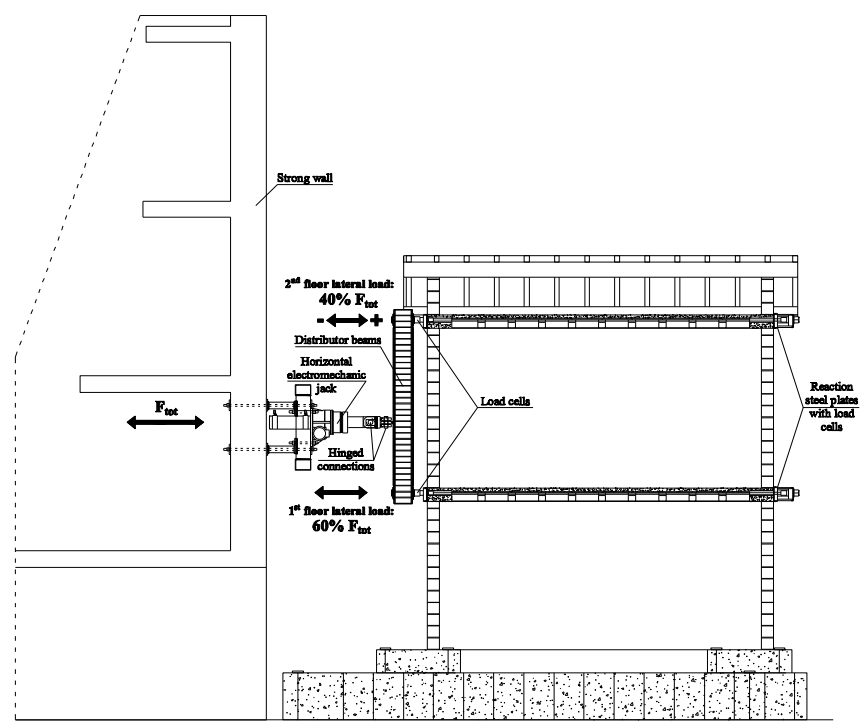

Fig. 9. Schematization of HCB masonry building rig.

\subsubsection{Test sequence}

The control parameter for each longitudinal wall was the drift, i.e. the average top floor displacement divided by the height of the second floor $(5685 \mathrm{~mm})$.

The masonry building was subjected to a sequence of test cycles in which the maximum top displacement was gradually increased until the maximum desired drift for the cycle was achieved. In every run, the desired horizontal target displacement was applied in both directions starting and ending at the zero position. Before cracking occurrence, every cycle was composed by one or two identical runs; after cracking, the number of runs in each cycle was increased to three.

The sequence of target top floor drift and corresponding displacements adopted for the test on unstrengthened building is shown in Figure 10.

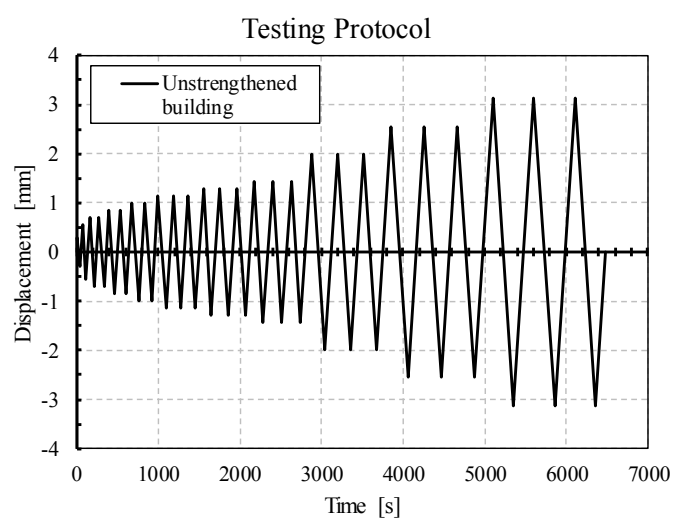

Fig. 10. Sequence of displacements applied to the second floor of the un-strengthened building. 


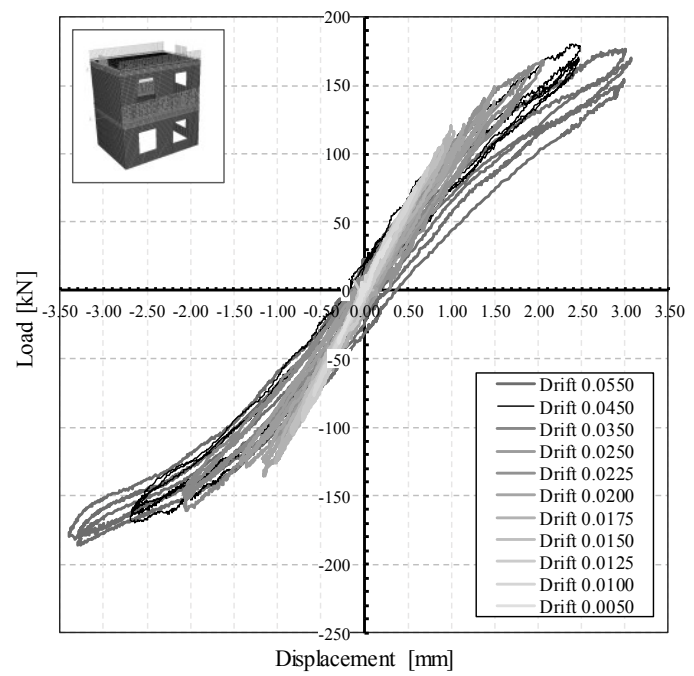

Fig. 11. Lateral load-displacement cyclic response of the unstrengthened building.

\subsubsection{Test results}

The lateral load (V) vs. displacement $(\delta)$ hysteretic curves obtained from the test on un-strengthened building are plotted in Figure 11. The un-strengthened building behavior was governed by the in-plane walls response, particularly by a shear failure of masonry piers. The first part of the response was linear until diagonal cracks started to grow in the central area of the piers of longitudinal walls of ground floor, causing a gradual loss of stiffness that led to the attainment of the maximum capacity. The building response presented a progressive reduction of the lateral stiffness in both loading directions; moreover in the positive one a capacity decrease after the peak can also be observed. These reductions were due to the formation of new shear cracks and cracks starting from the corner of the openings due to the rotation of external piers (see Figure 12). The pre-damage of un-strengthened building was reached and so the test was interrupted waiting for the second part of the test, that will be carry out after the application of $25 \mathrm{~mm}$ of SFRM on the external surface of the specimen.

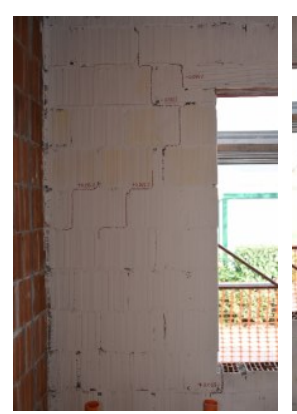

[I]

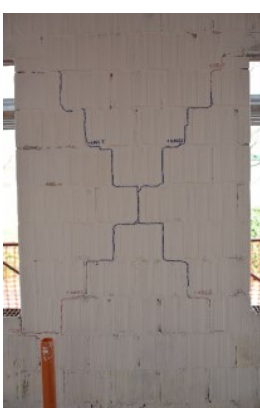

[II]

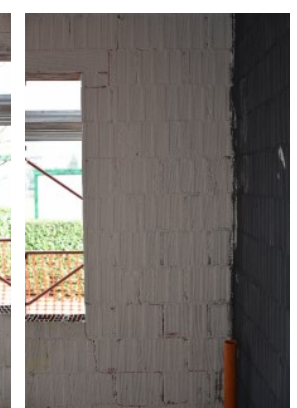

[III] (a): Inside view of Est façade at ground floor at the end of experimental test

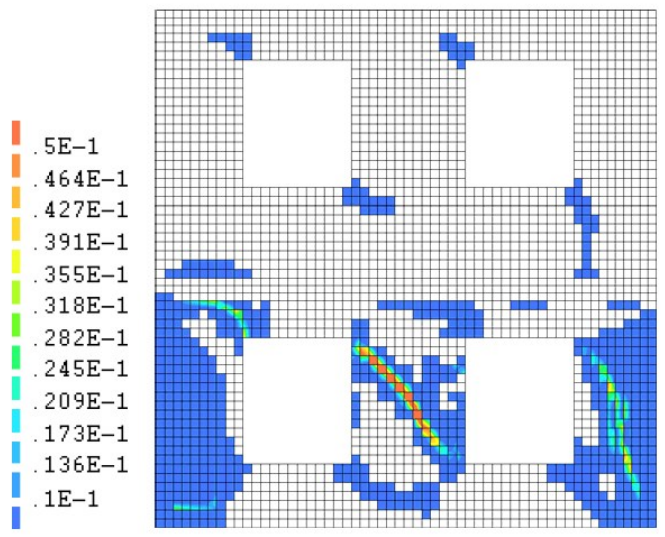

$[\mathrm{III}] \quad[\mathrm{II}] \quad[\mathrm{I}]$

(b): Outside view of Est façade at the collapse of numerical analysis (+ loading direction)

Fig. 12. Experimental crack pattern (a) and numerical contour of principal tensile post-cracking strains (b).

\subsubsection{Comparison with numerical prediction}

Figure 13 reports the comparison between experimental and numerical lateral load-displacement curves. The results obtained from Non-Linear Finite Element Analyses (NLFEAs) are in good agreement with the experimental results in term of initial stiffness, whereas the first cracking and maximum loads are slightly underestimated. The good agreement between the experimental and numerical crack patterns (plotted in terms of tensile cracking strain) is shown in Figure 13. As expected by the loading distribution proportional to floor mass, the cracks are localized at the ground floor of the structures, particularly on the piers of the longitudinal walls. As an examples, the Est façade was selected for the comparison. The central pier showed a diagonal shear failure, while the external ones exhibited a rocking mechanism with cracks starting from the corner of the openings. The pier farthest from the strong wall (named as [I] in Figure 13), showed also an incipient diagonal shear crack, as confirmed by the numerical analysis.

\section{Reinforced concrete bridge pier}

The test specimen represents a bridge pier (23.32 $\mathrm{m}$ tall) deforming in single curvature, supporting three singlespan box girders (Figures 14 and 15). The real bridge pier has a rectangular cross section of $600 \times 250 \mathrm{~cm}$ with two internal cells of $210 \times 130 \mathrm{~cm}$; therefore the wall thickness of the hollow cross section is $60 \mathrm{~cm}$.

The reinforcement in the critical section consists of $314 \varnothing 26$ longitudinal bars and Ø16 transverse reinforcements, spaced $100 \mathrm{~mm}$, with a concrete cover of $40 \mathrm{~mm}$. The cross-section area is equal to $9.38 \mathrm{~m}^{2}$ while the total longitudinal reinforcement area is $164,588 \mathrm{~mm}^{2}$, corresponding to a reinforcement ratio of $1.75 \%$. 


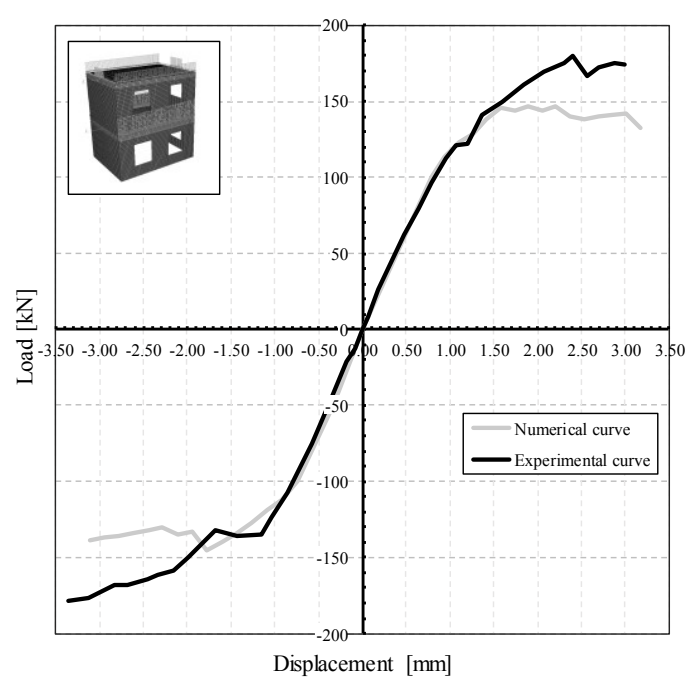

Fig. 13. Lateral load-displacement curves of the building: comparison between experimental and numerical results.

A geometric scale factor of 4 has been used to obtain the test specimen's cross section, equal to $150 \times 63 \mathrm{~cm}$ with two internal cells of $53 \times 32 \mathrm{~cm}$. The wall thickness of the hollow cross section is $15 \mathrm{~cm}$. The height of the $\mathrm{RC}$ specimen is $6.22 \mathrm{~m}$. The reinforcement consists of $66 \varnothing 14$ longitudinal bars and Ø8 transverse reinforcements (spaced $100 \mathrm{~mm}$ ) with a concrete cover of $10 \mathrm{~mm}$. The cross-section area is equal to $0,596 \mathrm{~m}^{2}$ and the total longitudinal reinforcement area is 10,160 $\mathrm{mm}^{2}$ corresponding to a reinforcement ratio of $1.70 \%$.

A new layer of HPFRC has been designed to strengthen/seismic retrofit the bridge pier considered under-performing for a new design-level of the seismic action. The new layer of HPFRC has a thickness of $30 \mathrm{~mm}$ and was placed directly around the RC specimen with the help of lightweight formworks. The cross section area of the reinforcement is $113,100 \mathrm{~mm}^{2}$ equal to the $20.92 \%$ of the cross-section area of the existing element. An Optimized Reinforcement (OR) was provided to the new HPFRC layer for transferring the base moment to the foundation. In particular, the OR is designed to yield when the HPFRC reaches its tensile strength, thus providing additional ductility to the section. The OR consist of $26 \varnothing 12$ longitudinal bars (spaced $100 \mathrm{~mm}$ ) with a concrete cover of $10 \mathrm{~mm}$. The reinforcement ratio considering both the existing concrete element and the new reinforcing layer is equal to $2.10 \%$. The OR is placed along the critical zone $(1 / 3$ of the height of the jacketing) and is anchored in the foundation.
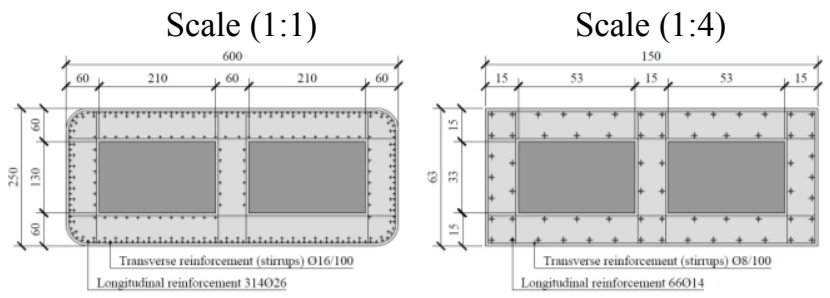

Fig. 14. Cross-section of the bridge pier at the base, measures in centimetres.

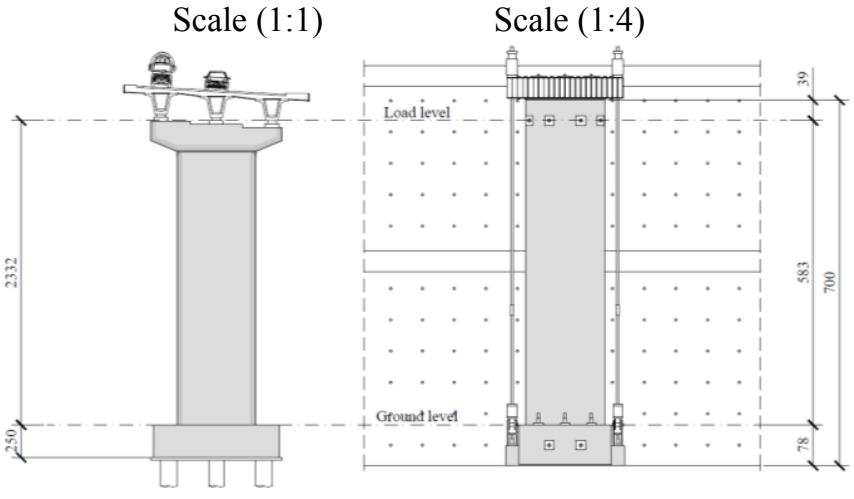

Fig. 15. Front view of the bridge pier, measures in centimetres.

\subsection{Analytical prediction}

\subsubsection{Load-displacement curves}

The structural response of the bridge pier has been predicted by means of a non-linear analysis based on the sectional theory. The load-displacement curve, shown in Figure 16 has been determined by the integration of the curvature due to the bending moment in the pier considered as a cantilever loaded at the end. The nonlinear behavior of materials was considered in the determination of the moment-curvature relationship according to Eurocode 2 [14] (Figure 17). Despite the rather simplified approach, this method can provide a first estimation of the deformations and loads that expected during the test.

Figure 16 exhibits the load-lateral displacement curves of the test specimen under static uni-directional loading: it can be noticed that the use of the $30 \mathrm{~mm}$ HPFRC layer increases the failure load of about $25 \%$ and the maximum displacement of about $66 \%$. When using HPFRC $+\mathrm{OR}$, the load capacity increases of about $75 \%$ and the ductility of about $91 \%$. The maximum lateral load, in this case, is about $454.2 \mathrm{kN}$ and the maximum lateral displacement is about $244.0 \mathrm{~mm}$.

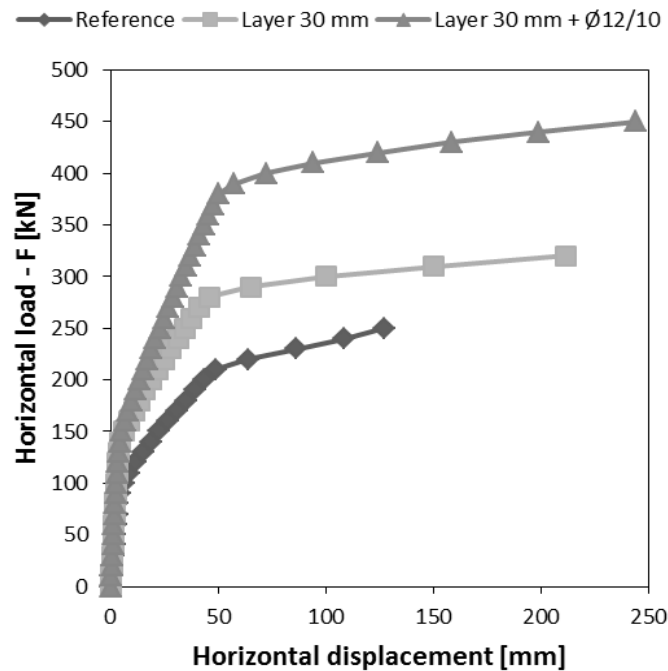

Fig. 16. Horizontal load - horizontal displacement curve: unreinforced element (reference), reinforced element with HPFRC, and reinforced element with HPFRC with optimized reinforcement (layer $30 \mathrm{~mm}+\varnothing 12 / 10$ ). 


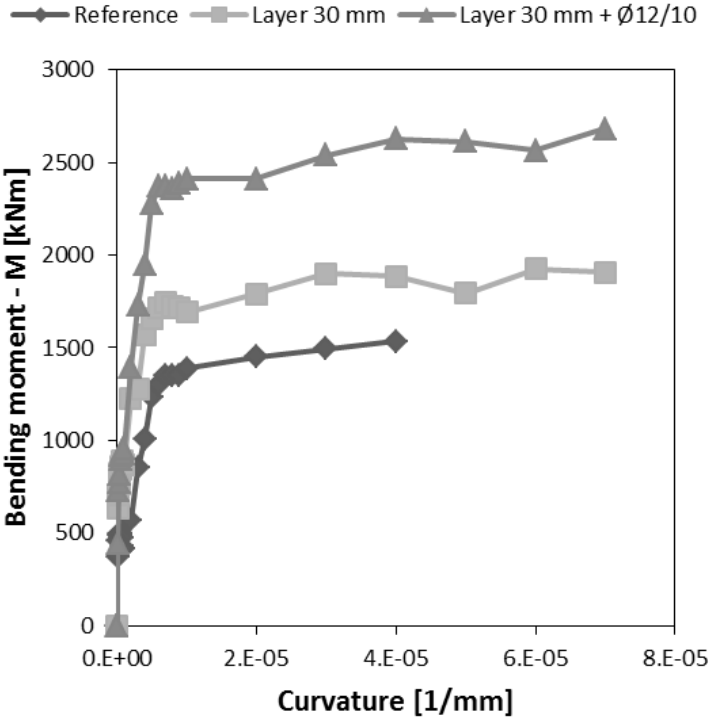

Fig. 17. Bending moment - curvature curve: unreinforced element, reinforced element with HPFRC, and reinforced element with HPFRC with optimized reinforcement.

\subsubsection{M-N interaction diagram}

The global response of the test specimen can be further investigated by the calculation of the bending moment axial force interaction diagram, as shown in Figure 18. This diagram is often adopted by structural designers for sectional verification at ULS; it can be easily determined according to fib Model Code 2010 [?], by considering the mechanical performance of the materials (both in compression and in tension). One should notice that the increment in the flexural capacity of the members reaches is maximum is $105 \%$ with HPFRC only and becomes $138 \%$ when using additional basereinforcement.

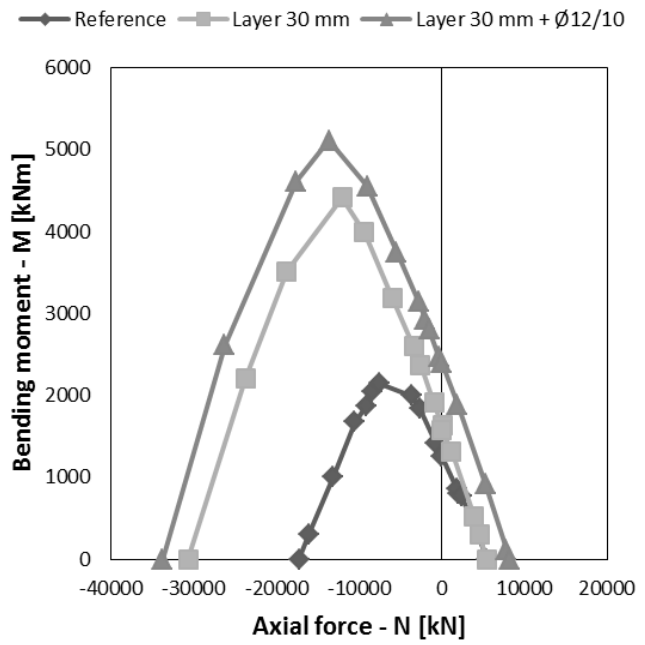

Fig. 18. Bending moment - axial load interaction diagram: unreinforced element, reinforced element with HPFRC, and reinforced element with HPFRC with optimized reinforcement.

\subsection{Experimental program}

\subsubsection{Test specimen}

The test was carried out at the laboratory for testing materials of the University of Brescia.

The concrete pier was cast horizontally in wooden formworks with a single batch of concrete (therefore, without cold joints). The specimen was cured for 28 days in the laboratory and, then, positioned vertically to be tested.

Before applying the HPFRC layer, the specimen was sandblasted to obtain a very rough surface $\left(\mathrm{R}_{\mathrm{t}} \geq 3.0 \mathrm{~mm}\right.$ [3]) and the OR was connected to the specimen foundation by means of chemical anchors.

The HPFRC jacket was made on site with the help of a planetary mixer. The pouring of the HPFRC layer was made in four stages using climbing lightweight formworks. Across cold joints, local additional reinforcement was provided for better connecting the different layers.

The phased casting of HPFRC was necessary for limiting the pressure on the formworks and to avoid the risk of honeycomb. The choice of lightweight formworks was motivated by the low friction coefficient of the polymeric material, for an easy placing of HPFRC, and the reduced weight, for a faster assembly and disassembly of the formworks during the real application. After removal of formworks, the jacketing was cured for 7 days by surface wetting and wrapping with a plastic sheet.

\subsubsection{Test program}

The specimen was cyclically loaded under a drift ratiocontrolled protocol (see Table 1). The $\operatorname{drift}(\theta)$ was defined as the ratio between the lateral displacement (d) at the point of application of the horizontal load $(\mathrm{H})$ and the distance between the same point at the base of the element.

Two test were performed on the bridge pier; the first test, carried out before the application of the jacketing, was performed under service loads, with a maximum drift equal to $0.2 \%$. The second test, after the application of the jacketing, was carried out up to failure which occurred at a maximum drift of $3.4 \%$.

Aim of the first test was to simulate the damage accumulated during service life of the bridge pier due to wind pressure and vehicle loads. Aim of the second test was the evaluation of the bearing capacity of the strengthened element.

\subsubsection{Materials properties}

Table 2 shows the experimentally determined compressive and tensile strength as well as the elastic modulus of NSC and of HPFRC. Compressive strength of NSC was measured after 28 days, for strength class determination, after 210 days, at the beginning of the first test (un-strengthened specimen), and after 270 days, at the beginning of the second test (strengthened 
specimen). According to Eurocode 2 [14] strength class of NSC was C25/30 while strength class of HPFRC was C90/105.

Table 1. Protocol for cyclic Tests 1 and 2.

\begin{tabular}{|c|c|c|c|}
\hline Test 1 & $\begin{array}{c}\mathbf{d} \\
{[\mathbf{m m}]}\end{array}$ & $\begin{array}{c}\boldsymbol{\theta} \\
{[\mathbf{\%}]}\end{array}$ & Cycles \\
\hline Step 1 & 2.5 & 0.05 & 3 \\
\hline Step 2 & 5 & 0.1 & 3 \\
\hline Step 3 & 12.5 & 0.25 & 3 \\
\hline Test 2 & $\begin{array}{c}\mathbf{d} \\
{[\mathbf{m m}]}\end{array}$ & $\begin{array}{c}\boldsymbol{\theta} \\
{[\mathbf{\%}]}\end{array}$ & Cycles \\
\hline Step 1 & 2.5 & 0.05 & 3 \\
\hline Step 2 & 5 & 0.1 & 3 \\
\hline Step 3 & 10 & 0.2 & 3 \\
\hline Step 4 & 15 & 0.25 & 3 \\
\hline Step 5 & 20 & 0.35 & 3 \\
\hline Step 6 & 25 & 0.4 & 3 \\
\hline Step 7 & 50 & 1.0 & 3 \\
\hline Step 8 & 75 & 1.3 & 3 \\
\hline Step 9 & 100 & 1.7 & 3 \\
\hline Step 10 & 125 & 2.1 & 3 \\
\hline Step 11 & 150 & 2.6 & 3 \\
\hline Step 12 & 200 & 3.4 & 3 \\
\hline
\end{tabular}

Table 2. Main mechanical and physical properties of NSC and HPFRC

\begin{tabular}{|l|c|c|c|c|}
\hline & \multicolumn{3}{|c|}{ NSC } & HPFRC \\
\hline Age, days & 28 & 210 & 270 & 28 \\
\hline $\begin{array}{l}\text { Compressive } \\
\text { strength, MPa }\end{array}$ & 42.5 & 48.4 & 49.5 & 136.3 \\
\hline $\begin{array}{l}\text { Indirect tensile } \\
\text { strength, MPa }\end{array}$ & - & 3.4 & 3.5 & 14.2 \\
\hline $\begin{array}{l}\text { Modulus of } \\
\text { elasticity, MPa }\end{array}$ & - & 34,510 & 36,035 & 44,879 \\
\hline
\end{tabular}

Post-cracking performance of HPFRC was determined by means of three-point bending testing on notched beams at the time of the second test (Figure 19), according to EN 14651. Flexural residual strengths significant for $\operatorname{SLS}\left(f_{R 1}\right)$ and for $\operatorname{ULS}\left(f_{R 3}\right)$ were 10.4 $\mathrm{MPa}$ and 6.9 $\mathrm{MPa}$, respectively (average values).

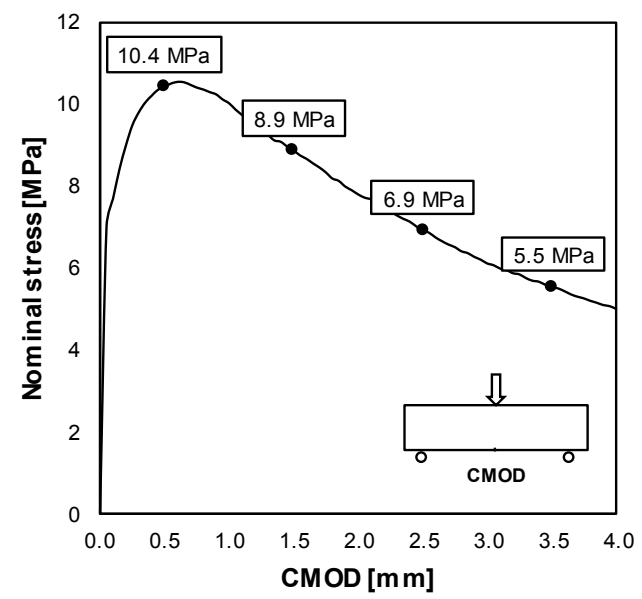

Fig. 19. Average response curve of HPFRC (3 specimens) under three point bending according to EN 14651:2005.

\subsubsection{Experimental results}

Figure 20 shows the seismic response of un-strengthened specimen; positive displacements correspond to a movement toward the strong wall (northward direction).

The strengthened specimen reached a maximum load of $451 \mathrm{kN}$ during the cycle with $\theta=3.4 \%(\mathrm{~d}=200 \mathrm{~mm})$ in the northward direction, where the lateral load continued growing up to the end of the test. In the southward direction the load reached instead a maximum value of $407 \mathrm{kN}$ during cycle with $\theta=1.7 \%(\mathrm{~d}=100 \mathrm{~mm})$ followed by a reduction $(-12 \%)$ up to $360 \mathrm{kN}$ with $\theta=3.4 \%$. After reaching the maximum drift, buckling of the jacketing occurred at the base of the south face (front) due to a local delamination of the HPFRC jacketing. As a consequence, a reduction of the stiffness of the element was observed and the test was interrupted to avoid any dangerous collapse.

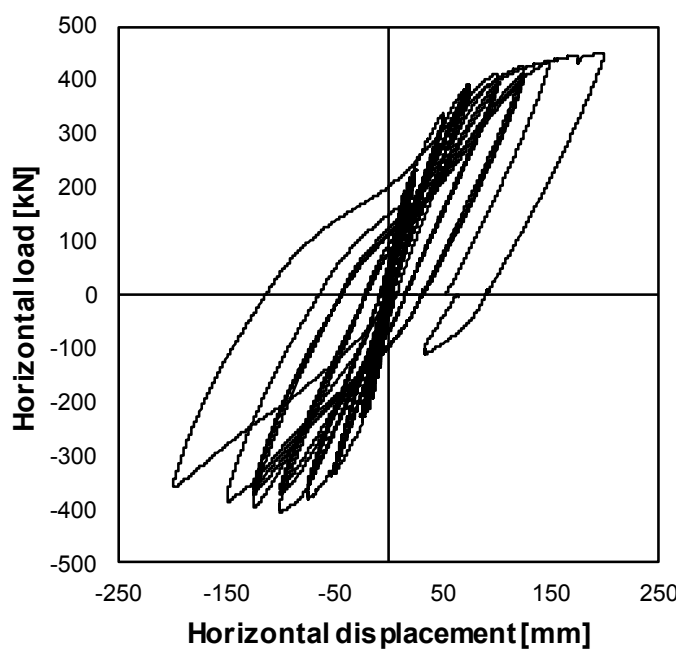

Fig. 20. Load vs. horizontal displacement response of the strengthened specimen (with additional reinforcement).

Figure 21 presents the development of cracks on the south face (front) of the strengthened specimen. The HPFRC showed an excellent ability to control cracking: a diffused pattern of micro-cracks developed up to $\theta=$ $1.7 \%$. Early cracks near the base of the element were observed at $\theta=0.1 \%(\mathrm{~d}=5 \mathrm{~mm})$ while first splitting cracks were observed at $\theta=0.3 \%(\mathrm{~d}=15 \mathrm{~mm})$. At a drift $\theta=1.7 \%$ a crack formed on the base section, where HPFRC jacketing was anchored to the $\mathrm{RC}$ basement. For higher drift values, no additional cracks formed but those already formed developed due to the yielding of reinforcement bars present in the jacketing. A few cracks near the base of the jacketing continued growing with a visible accumulation of the damage. No HPFRC spalling or fracture of reinforcements were observed at the end of the test. 

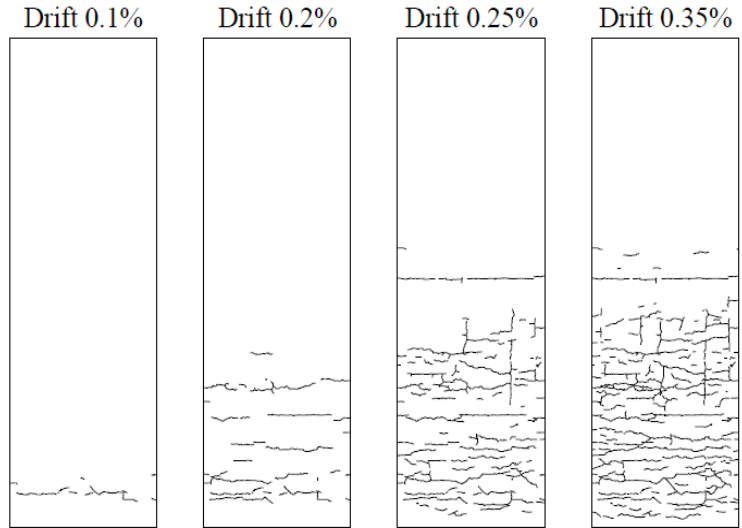

Drift $0.4 \%$
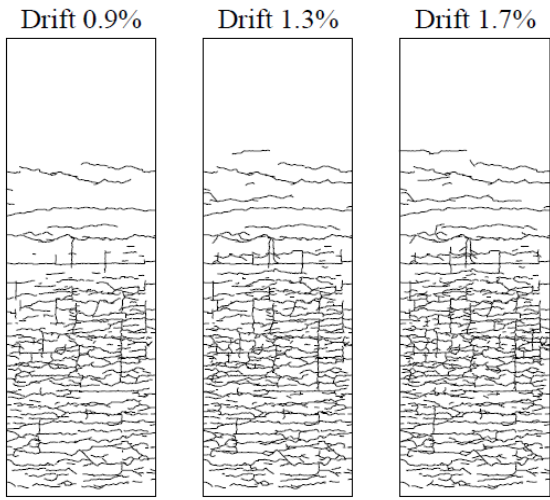

Fig. 21. Crack pattern on the south face (front) of the strengthened specimen.

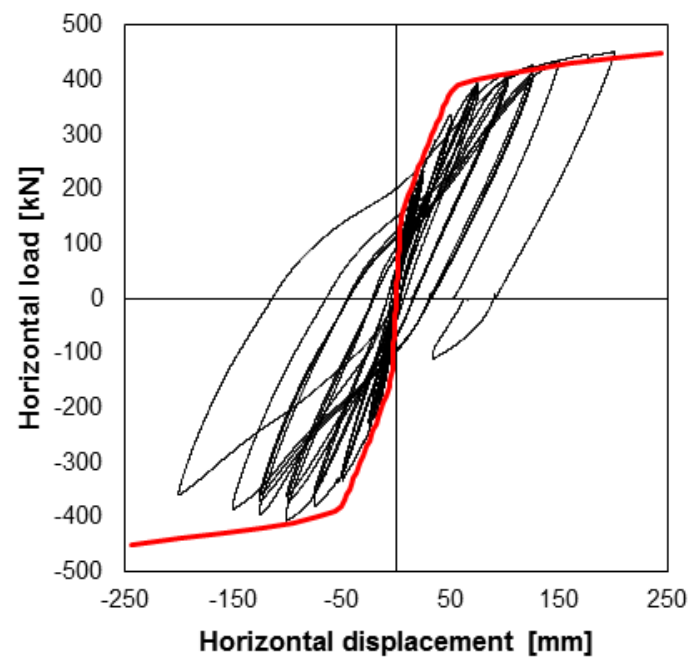

Fig. 22. Structural response of the strengthened specimen compared to the predicted response (thick line).

\subsubsection{Comparison with analytical prediction}

The experimental response of the strengthened specimen is eventually compared with the analytical predictions. It can be noticed that the overall response of the strengthened specimen shows a good agreement with the prediction of the analytical model adopted. The loaddisplacement curve, shown in Figure 22 with a thick line, were determined by the integration of the curvature, as shown in Section 3.1.1. The non-linear behaviour of materials was considered for determining the momentcurvature relationship according to Eurocode 2 [14].

\section{Concluding remarks}

Nowadays there is a growing interest on structural rehabilitation of existing structures so that international building codes are devoting an increasing attention to this topic.

Existing buildings are made of either masonry or reinforced concrete while existing infrastructures are mainly made of reinforced concrete.

Valuable and reliable strengthening methods are required for providing structural safety and durability to existing buildings. Among the new strengthening materials, Ultra High Performance Fibre Reinforced Concrete, used as external jacketing, raises particular interest since it improves both the resistance and the durability of the existing structure.

In the present paper, some case studies referring to a masonry building and a RC bridge pier are presented.

Based on the numerical and experimental results herein obtained, the following conclusion can be drawn:

- FRC represent an efficient solution for repairing and strengthening masonry or RC structures.

- In masonry structures that were originally designed without considering the seismic loads, a thin layer of FRC, used as an external plaster, can remarkably enhance both the in-plane and out-of-plane seismic resistance of masonry walls.

- In RC bridge piers, FRC can be used as an external jacket able to increase the bearing capacity for both vertical and horizontal loads.

- In addition to the bearing capacity, FRC also enhances cracking behavior of the structural element (i.e. reduced crack opening), thus providing a new service life to the structure.

The Authors wish to express their gratitude and sincere appreciation to Delta Phoenix SrL and to ItalcementiHeidelberg Group, for their financial support.

A special acknowledgement goes to the Colleagues of the Structural Design group of the University of Brescia and in particular to Prof. Fausto Minelli, Dr. Antonio Conforti, Dr. Luca Facconi, Dr. Adriano Reggia and to Eng. Sara Lucchini for their valuable support.

\section{References}

1. M. Di Prisco, G. Plizzari, L. Vandewalle, Fibre reinforced concrete: new design perspectives, Materials and Structures, 42 (9), 1261-1281 (2009).

2. A. Reggia, F. Macobatti, F. Minelli, G. A. Plizzari, S. Sgobba, Proceedings of the 4th International Conference on Concrete Repair, Rehabilitation and Retrofitting (ICCRRR-4, 2015)

3. Fédération Internationale du Béton, fib Model Code for Concrete Structures 2010, Final Complete Draft, fib bulletins 65 and 66 (2012).

4. Tomaževič, M., Weiss, P., Velechovsky, T., The influence of rigidity of floors on the seismic behavior of old stone-masonry building, European Earthquake Engineering, 3, 28-41 (1991). 
5. Magenes, G., Calvi, G.M., Kingsley, G.R., 1995. Experimental and numerical investigation on a brick masonry building prototype - numerical prediction of the experiment. University of Pavia, Italy.

6. Benedetti, D., Carydis, P., Pezzoli, P., Shaking table test on 24 masonry buildings, Earthquake Engineering \& Structural Dynamics, 27, 67-90 (1998).

7. Dolce, M., Ponzo, F. C., Goretti, A., Moroni, C., Nigro, D., Giordano, F., De Canio, G., Marnetto, R., $3 \mathrm{D}$ dynamic tests on $2 / 3$ scale masonry buildings upgraded with different systems, Proceedings of 14th World Conference on Earthquake Engineering, Beijing, China (2008).

8. Mazzon, N., Chavez, C. M., Valluzzi, M. R., Casarin, F., Modena, C., Shaking table test on multileaf stone masonry structures: Analysis of stiffness decay, Advanced Materials Research, 133, 647-652 (2010).

9. Magenes, G., Penna, A., Galasco, A., A full-scale shaking table test on a two-storey stone masonry building, 14th European Conference on Earthquake Engineer., Paper n.1432. Ohrid, Macedonia (2010).
10. Magenes, G., Penna, A., Senaldi, I. E., Rota, M., Galasco, A., Shaking table test of a strengthened full-scale stone masonry building with flexible diaphragms, Int. Jour. of Arch. Heritage: Conserv., Analysis, and Restor., 8(3), 349-375 (2014).

11. Italian Ministry of Infrastructures and Transportations, Decree 14 gennaio 2008, Norme tecniche per le costruzioni (2008).

12. Facconi, F., Conforti, A., Minelli, F., Plizzari, G. A., Improving shear strength of unreinforced masonry walls by nano-reinforced fibrous mortar coating, Materials and structures, 48(8), 2557-2574 (2014).

13. Diana 10.1. User's manual. TNO DIANA BV, Delft, The Netherlands; 2016.

14. CEN, EN 1992-1-1: Eurocode 2. Design of concrete structures. Part 1-1: General rules and rules for buildings, (2005). 